\title{
Heart defects and ocular anomalies in children with Down's syndrome
}

\author{
N R Bromham, J M Woodhouse, M Cregg, E Webb, W I Fraser
}

Br J Ophthalmol 2002;86:1367-1368

Aims: To investigate whether ocular anomalies are associated with congenital heart defects in children with Down's syndrome.

Methods: 58 children with Down's syndrome were entered into a retrospective observational study. Children were assigned to heart defect groups based on medical records. Optometric tests had previously been carried out at the homes of the children.

Results: A relation between congenital cardiac defects, myopia, and nystagmus was observed. Heart problems were not related to accommodative insufficiency, hyperopia, or strabismus.

Conclusion: In children with Down's syndrome heart defects were associated with both myopia and nystagmus.

O phthalmological anomalies are common in individuals with Down's syndrome including refractive error, nystagmus, ${ }^{2}$ strabismus, ${ }^{3}$ and cataract. ${ }^{4}$ The incidence and severity of these defects is variable and it is not known why some individuals develop ocular problems and others do not, given that the underlying chromosomal abnormality is almost always identical.

Some authors argue that the characteristic traits of Down's syndrome result from a combination of gene dosage effects as a result of extra copies of genes on chromosome $21 .{ }^{5}$ Variability in the ocular features of Down's syndrome could relate to polymorphism in these genes. Others believe the extra chromosomal material causes a generalised disruption in the genetic balance of cells. ${ }^{6}$ From this viewpoint non-specific developmental instability following aneuploidy accounts for ocular anomalies in Down's syndrome.

Refractive error is common in Down's syndrome, showing great variability between individuals. Gardiner ${ }^{7}$ suggested that the myopia seen in some children with Down's syndrome was related to the characteristic congenital heart defects of the syndrome. Pires da Cunha and Belmiro de Castro Moriera ${ }^{8}$ found that children and teenagers with Down's syndrome and cardiac malformations had more myopia than those without such malformations. These studies suggest that heart defects are related in some way to the ocular manifestation of Down's syndrome. This study aimed to investigate the potential association between congenital heart defects and optometric anomalies in a group of children with Down's syndrome.

\section{PATIENTS AND METHODS}

A retrospective observational study was conducted at the Department of Optometry and Vision Sciences of Cardiff University. The recruitment and experimental protocols for the study were conducted in compliance with the Declaration of Helsinki and approved by local ethics research committees.

Since 1991 the visual development of a cohort of children with Down's syndrome has been studied at the Department of Optometry and Vision Sciences of Cardiff University. The parents of the children from this cohort were contacted by post and asked about any history of heart problems in their child. Medical records were checked for those children who were reported as having a heart defect. A total of 58 children, aged between 1 and 9 years, were classified into groups according to the heart defects recorded in the medical records. All children had full trisomy 21 .

Optometric tests were carried out at the homes of the children. Refractive error was measured using Mohindra retinoscopy. ${ }^{9}$ The equivalent sphere of the right eye was used to for statistical analysis. Myopia was defined as a refraction of $-0.50 \mathrm{D}$ or greater, and hyperopia as a refraction of $+2.00 \mathrm{D}$ or greater.

Accommodation was measured using modified Nott dynamic retinoscopy. ${ }^{10}$ The accommodative error index $(\mathrm{AEI})^{11}$ was used to describe accommodative inaccuracy. AEI greater than 0.75 dioptres was considered as accommodative insufficiency.

Eye motility was examined by observing the child's eye movements when fixating a moving target. The presence of nystagmus was noted. Eye alignment was assessed using Hirchberg's corneal reflex and the cover test at near.

Statistical analysis was conducted using the $\chi^{2}$ test. Fisher's exact test was used where low subject numbers precluded the use of the $\chi^{2}$ test.

Table 1 Frequency of ocular anomalies both in the group as a whole and in the children with heart defects

\begin{tabular}{lll}
\hline Ocular abnormality & Total cases & $\begin{array}{l}\text { Cases with heart } \\
\text { defects }\end{array}$ \\
\hline Accommodative insufficiency: AEI $>0.75$ dioptres & 46 & 26 \\
Hyperopia $>2$ dioptres & 27 & 13 \\
Myopia $>0.5$ dioptres & 6 & 6 \\
Anisometropia $>2$ dioptres & 1 & 1 \\
Esotropia & 13 & 7 \\
Intermittent esotropia & 12 & 7 \\
Intermittent exotropia & 2 & 2 \\
Nystagmus & 11 & 9 \\
\hline
\end{tabular}




\section{RESULTS}

The frequency of ocular anomalies and heart defects is shown in Table 1. A total of 31 children had congenital heart defects; 27 children had no such defects. The most common ocular finding was accommodative insufficiency followed by refractive error, strabismus, and nystagmus.

Myopia and nystagmus were significantly associated with heart defects. There was no significant association between heart defects and accommodative insufficiency, hyperopia, or strabismus.

All six observed cases of myopia were seen in children with heart defects. The frequency of myopia among the children with cardiac defects was significantly greater than among the children with no heart problems $(p=0.018$, Fisher's exact test).

The children with cardiac defects were more likely to have nystagmus than those without cardiac problems. Of the 11 children with nystagmus, nine had a heart defect $\left(p=0.026, \chi^{2}\right.$ test). The myopic children were also more likely to have nystagmus than the non-myopes; five of the six myopes in the cohort had nystagmus ( $\mathrm{p}=0.001$, Fisher's exact test).

\section{DISCUSSION}

This study found both myopia and nystagmus to be associated with heart defects in children with Down's syndrome. Heart defects were not related to accommodative insufficiency, hyperopia, or strabismus in our cohort.

The clinical association between endocardial cushion defects and trisomy 21 suggests that genes located on chromosome 21 contribute to the development of the heart. ${ }^{12}$ Several genes have been proposed as candidates for congenital heart disease in Down's syndrome, consistent with the "genedosage" effects hypothesis of Down's syndrome traits. ${ }^{5}$ Genetic polymorphisms related to heart defects could confer an increased risk of myopia. Davies et al $^{13}$ reported an association between variation in the COL6Al gene region and congenital heart defects in Down's syndrome. COL6Al codes for part of collagen VI, a component of many ocular tissues. ${ }^{14}$ Down's syndrome cell adhesion molecule (DSCAM) has also been considered as a candidate gene for heart defects in Down's syndrome. ${ }^{15}$ DSCAM is widely expressed in the developing nervous system, including the visual pathways, and may be involved in the regulation of myelination. ${ }^{16}$

The co-occurrence of particular traits in Down's syndrome may reflect increased developmental instability rather than specific gene-dosage effects. Amplified sensitivity to genetic and environmental forces during early development could result in both heart and ocular abnormalities. Studies of risk factors in early pregnancy and cardiac malformations in infants with Down's syndrome have proposed maternal cigarette smoking ${ }^{17}$ and maternal age ${ }^{18}$ as risk factors. No studies have examined risk factors for ocular anomalies in Down's syndrome.

Myopia and nystagmus can occur following damage to the visual pathways. Their association with heart defects in the present study raises the possibility of such damage secondary to the cardiac problem. Using ophthalmoscopy the present study did not observe fundus abnormalities beyond the spoke-like blood vessel arrangement around the optic disc often seen in Down's syndrome. ${ }^{4}$ The pupils were not dilated in the present study and it is conceivable that some anomalies were not detected.

Children with Down's syndrome and heart defects were more likely than those without defects to develop myopia and nystagmus in the first 9 years of life. This is of significance to the clinician given the degree to which myopia can progress in Down's syndrome, especially since advances in the management of cardiac defects mean that most of these children are surviving early childhood. The Down Syndrome Medical Interest Group publishes ophthalmic surveillance guidelines for people with Down's syndrome. ${ }^{19}$ These recommend that visual behaviour is monitored by a paediatrician during the first year of life, with a formal ophthalmological review during the second year. Those with no abnormalities at the first review should have a further full ophthalmological review around the age of 4 years. We believe that adherence to these recommendations is important, especially for children with heart defects.

\section{ACKNOWLEDGEMENTS}

This work was supported in part by grants from the Community Fund in collaboration with Mencap, and by the Medical Research Council, UK. The authors thank Professor Mike Creasey of the Cytogenetics Department, University Hospital of Wales for his help in recruitment for the study. We also thank the children and their families for their participation.

\section{Authors' affiliations}

N R Bromham, J M Woodhouse, M Cregg, Department of Optometry and Vision Sciences, Cardiff University, Cardiff, UK

E Webb, Department of Child Health, University of Wales College of Medicine, Cardiff, UK

W I Fraser, Welsh Centre for Learning Disabilities, University of Wales College of Medicine, Cardiff, UK

Correspondence to: Nathan R Bromham, Department of Optometry and Vision Sciences, Cardiff University, Cardiff CF10 3NB, UK;

bromham@cf.ac.uk

Accepted for publication 19 July 2002

\section{REFERENCES}

1 Woodhouse JM, Pakeman VH, Cregg $M$, et al. Refractive errors in young children with Down syndrome. Optom Vis Sci 1997;74:844-51.

2 Wagner RS, Caputo AR, Reynolds RD. Nystagmus in Down's syndrome. Ophthalmology 1990;97:1439-43.

3 Haugen $\mathrm{OH}$, Hodvig $\mathrm{G}$. Strabismus and binocular function in children with Down syndrome. A population-based, longitudinal study. Acta Ophthalmol Scand 2001;79:133-9.

4 Fierson WM. Ophthalmological aspects. In: Van Dynke DC, Lang DJ, Heide F, et al, eds. Clinical perspectives in the management of down syndrome. 1st ed. New York: Springer-Verlag; 1990:26-54.

5 Reeves R, Baxter L, Richtsmeier J. Too much of a good thing: mechanisms of gene action in Down syndrome. Trends Genet 2001; 17:83-8.

6 Shapiro BL. Down syndrome-a disruption of homeostasis. Am J Med Genet 1983;14:241-69

7 Gardiner PA. Visual defects in cases of Down's syndrome and in other mentally handicapped children. Br J Ophthalmol 1967;51:469-74.

8 Pires da Cunha R, Belmiro de Castro Moriera J. Ocular findings in Down's syndrome. Am J Ophthalmol 1996;122:236-44.

9 Mohindra I. A technique for infant examination. Am J Optom Physiol Optics 1975:54:319-22.

10 Cregg M, Woodhouse JM, Pakeman VH, et al. Accommodation and refractive error in children with Down syndrome: cross-sectional and longitudinal studies. Invest Ophthalmol Vis Sci 2001;42:55-63.

11 Chauhan K, Charman WN. Single figure indexes for the steady-state accommodative response. Ophthalmic Physiol Opt 1995;15:217-21.

12 Klewer SE, Krob SL, Kolker SJ, et al. Expression of type VI collagen in the developing mouse heart. Dev Dyn 1998;211:248-55.

13 Davies GE, Howard CM, Farrer M, et al. Genetic variation in the COL6Al region is associated with congenital heart defects in trisomy 21 (Down's syndrome). Ann Hum Genet 1995:59:253-69.

14 Marshall G, Konstas A, Lee W. Collagens in ocular tissues. $\mathrm{Br} J$ Ophthalmol 1993;77:515-24.

15 Barlow GM, Chen XN, Shi ZY, et al. Down syndrome congenital heart disease: a narrowed region and a candidate gene. Genet Med 2001;3:91-101.

16 Saito Y, Akira O, Masashi M, et al. The developmental and aging changes of Down's syndrome cell adhesion molecule expression in normal and Down's syndrome brains. Acta Neuropathol 2000;100:654-64

17 Torfs CP. Christianson RE. Maternal risk factors and major associated defects in infants with Down syndrome. Epidemiology 1999;10:264-70.

18 Kallen B, Mastroiacovo P, Robert E. Major congenital malformations in Down syndrome. Am J Med Genet 1996;65: 160-6.

19 Dennis J, ed. DSMIG guidelines for essential medical surveillance. 2002. www.dsmig.org.uk/publications/guidelines.html (accessed 31 May 2002). 